\title{
Laparoscopic-assisted transversus abdominis plane block as an effective analgesic in total extraperitoneal inguinal hernia repair: a double-blind, randomized controlled trial
}

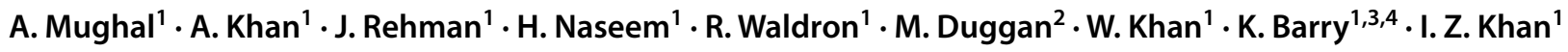

Received: 11 March 2018 / Accepted: 21 August 2018 / Published online: 1 September 2018

(c) The Author(s) 2018

\begin{abstract}
Purpose Laparoscopic inguinal hernia repair has facilitated early mobilization. Management of post-operative pain is paramount in these day case procedures. The aim of this study was to compare laparoscopic-assisted transversus abdominis plane (TAP) block with periportal local anaesthetic infiltration in managing post-operative pain.

Methods A double-blind, randomized controlled trial was conducted with patients undergoing elective laparoscopic inguinal hernia repair (January 2016-October 2017). The intervention group received laparoscopic-assisted TAP block with $30 \mathrm{ml}$ $0.25 \%$ Bupivacaine. The control group received $15 \mathrm{ml}$ of $0.5 \%$ Bupivacaine at the periportal sites. Primary outcome measure was assessment of post-operative pain scores using numerical rating on visual analogue scale (VAS) at rest and on coughing at $3 \mathrm{~h}$. Efficacy of TAP block was assessed as reduction in mean pain scores in the order of 2 points using the VAS.

Results 60 (57 males and 3 females) were enrolled; 30 patients were randomized to each group. Patient demographics, anaesthetic and surgical times were similar in both groups. Mean pain scores were significantly reduced in the intervention group at $3(3.1 \mathrm{vs} 1.1 p<0.001)$ and $6 \mathrm{~h}(4.1 \mathrm{vs} 1.7 p<0.001)$ at rest and on coughing at $3(4.8 \mathrm{vs} 2.1 p<0.001)$ and $6 \mathrm{~h}$ $(5.4$ vs $3.0 p<0.001)$. Patient satisfaction was higher $(8.0$ vs $6.8 p<0.001)$ and rescue analgesic requirements $(169.4 \mathrm{vs} 71.3$ $p<0.001)$ lower in the intervention group.

Conclusions This analysis has demonstrated the therapeutic benefit of laparoscopic-assisted TAP block in initial postoperative pain management for patients undergoing elective laparoscopic inguinal hernia repair.
\end{abstract}

Keywords Laparoscopic-assisted transversus abdominis Plane block · Periportal · Total extraperitoneal inguinal hernia repair · Visual analogue scale

A. Mughal

dr.afzaalmughal@gmail.com

1 Department of Surgery, Mayo University Hospital, Saolta University Healthcare Group, Castlebar, Co Mayo, Ireland

2 Department of Anaesthesia, Mayo University Hospital, Saolta University Healthcare Group, Castlebar, Co Mayo, Ireland

3 Discipline of Surgery, National University Ireland, Galway, Ireland

4 Programme Director for Speciality Training in General Surgery, Royal College of Surgeons in Ireland, Dublin, Ireland

\section{Introduction}

The annual rate for inguinal hernia repair ranges from 10 per 100000 of the population in the United Kingdom to 28 per 100000 in the United States [1]. There is ongoing debate about the efficacy of open mesh repair vs laparoscopic repair $[2,3]$. Minimally invasive laparoscopic approaches offer certain advantages over open repair including reduced post-operative pain, enhanced recovery and early return to work $[4,5]$. Regional blocks are an important component of multi-modal analgesia to enhance post-operative recovery. Transversus abdominis plane (TAP) block is a regional anaesthetic technique which provides effective analgesia to the parietal peritoneum as well as to the skin and muscles of the anterior abdominal wall. TAP block is delivered in the fascial plane between the internal oblique and transversus 
abdominis muscles targeting the somatic nerves T6-L1 which run in this plane [6-8].

Several techniques are currently used to deliver TAP blocks, including blinded double POP technique [6], ultrasound-guided [7] and laparoscopic-assisted approaches [9-11]. The latter was first described in 2011 by Chetwood et al. while performing laparoscopic nephrectomies [9]. The advantages of this technique include ease of performance, less dependency on specialized skill set or equipment and avoidance of intraperitoneal local anaesthetic infiltration [9-11].

The efficacy of ultrasound-guided TAP block and rectus sheath block has been previously investigated in laparoscopic inguinal hernia repair [12-14]. To the best of our knowledge, laparoscopic-assisted TAP block has not been utilized or evaluated prospectively in laparoscopic total extraperitoneal (TEP) repair of inguinal hernia as a component of multi-modal analgesia. The aim of the current study was to compare the efficacy of laparoscopic-assisted TAP block with conventional periportal infiltration of local anaesthetic in post-operative pain management for patients undergoing elective laparoscopic total extraperitoneal (TEP) inguinal hernia repair. Pain assessment was measured using the visual analogue scale $(0-10)$.

\section{Methods}

This double-blind randomized controlled trial was conducted at Mayo University Hospital (MUH), Ireland, from January 2016 to October 2017. MUH is a teaching hospital affiliated with the National University of Ireland, Galway. Ethical approval was obtained from the hospital research ethics committee and the trial was registered with Clinical Trials.gov (Trial Registration no. NCT02632136). For conducting the trial, CONSORT checklist was followed.

\section{Inclusion criteria}

All consecutive ASA grades I-III patients deemed medically fit to undergo elective unilateral laparoscopic total extraperitoneal (TEP) inguinal hernia repair between age 18 and 80 years were included in this study.

\section{Exclusion criteria}

Exclusion criteria were ASA grade IV, V; BMI $>40 \mathrm{~kg} / \mathrm{m} 2$; converted to open or transabdominal preperitoneal (TAPP) repair; bilateral inguinal hernia; coagulopathy; allergy to bupivacaine; diagnosis of "chronic pain syndrome"; known alcohol or substance abuse within the last 6 months; daily opioid intake.

\section{Randomization}

Using a computerized "random number table" technique, a randomization list was generated, and patients were allocated following the list order on the day of admission. The procedure and intervention were explained to each patient by the admitting doctor and informed consent was obtained before transfer to the operating room. General anaesthesia was induced with fentanyl $2 \mu \mathrm{g} / \mathrm{kg}$ and propofol 2 to $3 \mathrm{mg} / \mathrm{kg}$ intravenously (IV). Rocuronium was administered and the trachea was intubated. Anaesthesia was maintained with oxygen, air (50\%:50\%), and sevoflurane. Fentanyl $0.5 \mu \mathrm{g} / \mathrm{kg}$ was given on $20 \%$ increase in heart rate or mean blood pressure. For persistent tachycardia morphine $(0.05-0.1 \mathrm{~g} / \mathrm{kg})$ was administered. First dose of IV paracetamol $(1 \mathrm{~g})$ was given $30 \mathrm{~min}$ before the end of surgery. Ondansetron $(4 \mathrm{mg}) \mathrm{IV}$ was administered $15 \mathrm{~min}$ before the end of the surgery for all patients. The intervention group received laparoscopic-assisted TAP block with Bupivacaine and periportal sterile saline, and the control group, received laparoscopic-assisted TAP block with sterile saline and periportal infiltration of Bupivacaine (Fig. 1).

Two sets of syringes were prepared: $15-\mathrm{ml}$ syringes $\mathrm{x} 2$ for TAP block; 15-ml syringe $\mathrm{x} 1$ for periportal infiltration. Both operating and anaesthetic teams were blinded to the intervention received by each patient. This was assured for each patient enrolled in the study, as an independent clinical research fellow prepared the appropriate syringes in a designated sterile area on the day of surgery and without participating in any of the procedures. In addition, postoperative pain assessment was performed by a separate team of clinical research assistants $(3,6$ and $24 \mathrm{~h}$ ), unaware of the pre-operative intervention in each case.

\section{Laparoscopic-assisted TAP block}

The TAP block was performed by injecting local anaesthetic (22G blunt needle) anterior to the midaxillary line after establishing the space of Bogros [15] (Fig. 2). Digital pressure was applied to define the site of injection. The

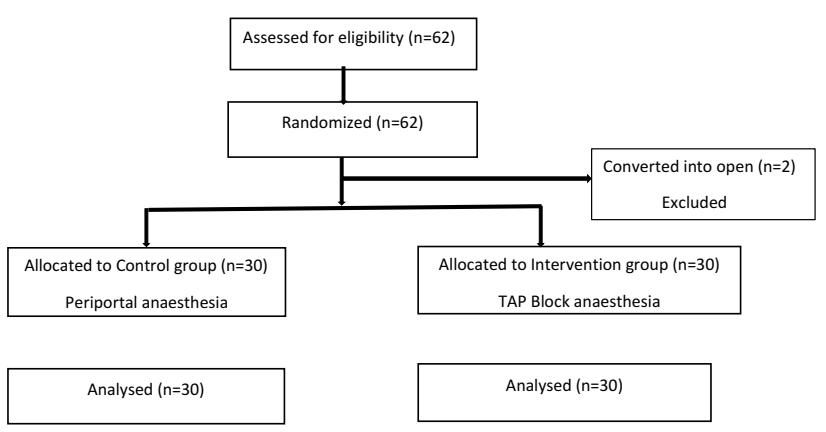

Fig. 1 Study flow diagram. TAP, transversus abdominis plane 


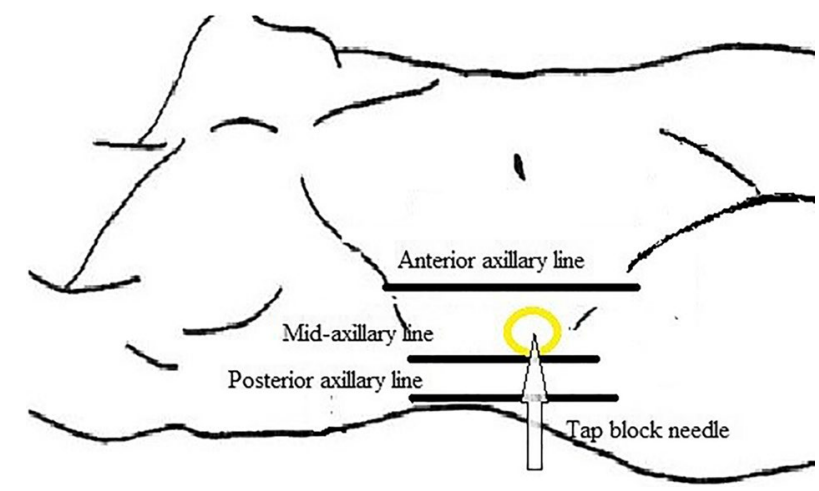

Fig. 2 Surface landmarks for TAP block. Needle is inserted anterior to midaxillary line

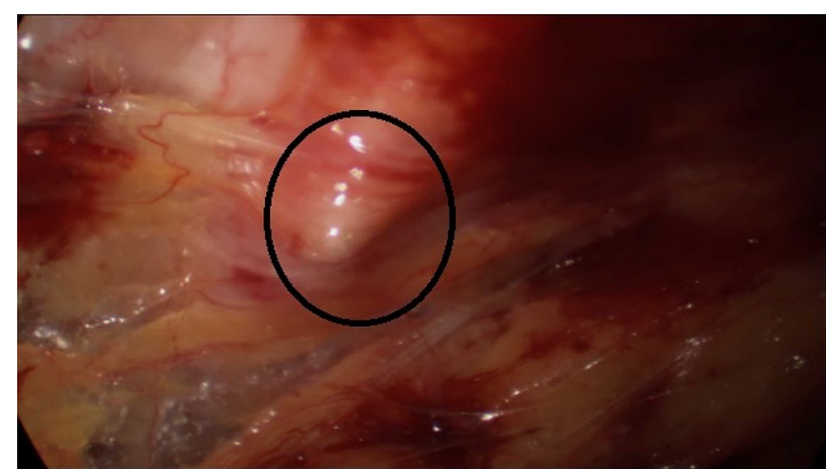

Fig. 3 Bulge after injection of local anaesthetic, visualized through laparoscope within the space of Bogros

needle was inserted at the site of injection until it was close to the transversalis fascia with slight tenting visible through the laparoscope. Then the plunger was withdrawn to exclude vascular placement and the local anaesthetic was infiltrated. The site of injection was inspected from within the space of Bogros. The presence of an internal bulge was regarded as the definitive point of the procedure (Fig. 3).

Fixed dose of Bupivacaine $75 \mathrm{mg}$ ( $30 \mathrm{ml}$ of $0.25 \%$ for the intervention group and $15 \mathrm{ml}$ of $0.5 \%$ for control group) was used. The intervention group received $30 \mathrm{ml}$ of $0.25 \%$ Bupivacaine and $15 \mathrm{ml}$ of normal saline at the three port sites before their insertion; $7 \mathrm{ml}$ for the camera port and $4 \mathrm{ml}$ for the two working ports. The control group received $30 \mathrm{ml}$ of normal saline in the transversus abdominus plane and $15 \mathrm{ml}$ of $0.5 \%$ Bupivacaine at the three port sites; $7 \mathrm{ml}$ for the camera port and $4 \mathrm{ml}$ for the two working ports.

All hernias were repaired using a knitted polypropylene pre-formed mesh (BARD 3DMAX). The mesh was secured with 2-3 absorbable tacks using a 5-mm fixation device (AbsorbaTack). Carbon dioxide was insufflated into the preperitoneal space at a rate of $4-6 \mathrm{~L} / \mathrm{min}$ to a pressure of $15 \mathrm{~mm}$. Three ports, one $10 \mathrm{~mm}$ for the laparoscopic camera and two 5-mm midline working ports were used.

\section{Post-operative pain management}

A standardized analgesic regimen was prescribed in the post-operative period. In the recovery room if patient pain score was more than 4 on VAS, intravenous morphine was prescribed $(0.05-0.1 \mathrm{~g} / \mathrm{kg})$. Total opioids used in the perioperative period were recorded. All patients received paracetamol $1000 \mathrm{mg} 6 \mathrm{~h}$ and single dose of Dexketoprofen $25 \mathrm{mg}$ at $8 \mathrm{~h}$ per-oral after induction of anaesthesia. This was constant for all patients. Rescue analgesia was offered when patient VAS score was more than 4 . For rescue analgesia, Tapentadol $75 \mathrm{mg} 6 \mathrm{~h}$ was prescribed. Maximum dose of Tapentadol prescribed was $300 \mathrm{mg}$.

\section{Study outcomes}

\section{Primary outcome}

The primary outcome in this study was assessment of postoperative pain scores both at rest and coughing at $3 \mathrm{~h} \mathrm{[10].}$ Pain assessment on coughing was designed to reflect pain induced by physical activity.

\section{Secondary outcomes}

Total rescue analgesic requirement, peri-operative morphine consumption and intra-operative fentanyl requirement were noted along with episodes of nausea or vomiting. Additionally, patient satisfaction levels with regards post-operative pain were also assessed by numerical rating scores (1-10). Additional time points were studied to investigate the pharmacological impact of Bupivacaine on pain scores over an extended period as this has not been reported using our laparoscopic-assisted TAP block technique previously. Pain was assessed at rest and coughing using the numerical visual analogue scale (VAS from 0 to 10) at 6 and $24 \mathrm{~h}$. Patients were contacted by telephone at $24 \mathrm{~h}$ to assess pain scores.

\section{Statistical analysis}

Sample size was calculated according to the primary outcome measure of post-operative pain assessment at three hours. An effect size estimate of reduction in mean pain scores of two points on the VAS was calculated based on our previous analysis of laparoscopic-assisted TAP block in laparoscopic cholecystectomy. ${ }^{10}$ Sample size was calculated using world health organization sample size determination software. Alpha value of 0.05 , power of $80 \%$ and standard deviation of 1.83 were utilized to calculate sample size; 30 patients were required in each arm to reach a power of $80 \%$ (Fig. 1). SPSS version 24 was used for data analysis. For continuous data, we used rank sum test and for categorical data, we used Chi-square test. Continuous data are presented as means with 
$\mathrm{SD}$ and categorical data are presented as frequencies with percentages; $p$ value of $<0.05$ was considered as significant. Per protocol analysis was conducted throughout.

\section{Results}

The total number of patients enrolled in the study was 62 . Two patients were subsequently excluded because of conversion to open repair and, therefore, excluded from statistical analysis (Fig. 1). Similar patient characteristics were observed between the control and intervention groups (Table 1). All patients were discharged on the day of surgery and there were no postoperative complications recorded at $6 \mathrm{~h}$.

\section{Primary outcome}

Pain scores were reduced at $3 \mathrm{~h}$ after laparoscopic hernia repair (TEP) with statistically significant $p$ values recorded both at rest $(p<0.001)$ and coughing $(p<0.001)$ comparing control and intervention groups (Table 2).

\section{Secondary outcomes}

Total rescue analgesic requirements were significantly reduced in the intervention group $(p<0.001)$. Intra-operative fentanyl requirement was also significantly reduced in the intervention group as compared with the control group $(p=0.004)$. Intra-operative morphine consumption was similar in both groups $(p=0.12)$ (Table 3$)$. The incidence of nausea and vomiting was similar in both groups. Of note, patient satisfaction scores $(p<0.001)$ were significantly higher in the intervention group as compared with the control group (Table 3).

Reduction in pain scores at rest was recorded at 6 $(p<0.001)$ and $24 \mathrm{~h}(p=0.035)$. Pain scores were reduced on coughing at $6 \mathrm{~h}(p=0.001)$. However, no significant reduction in pain scores was recorded $(p=0.09)$ on coughing at $24 \mathrm{~h}$ (Table 2).
Table 1 Patient demographics and clinical characteristics

\begin{tabular}{llll}
\hline & $\begin{array}{l}\text { Control group } \\
(n=30)\end{array}$ & $\begin{array}{l}\text { Intervention group } \\
(n=30)\end{array}$ & $p$ value \\
\hline $\begin{array}{l}\text { Mean anaesthetic time } \pm \text { SD (minutes) } \\
\text { Mean surgical time } \pm \text { SD (minutes) }\end{array}$ & $\begin{array}{l}76.8 \pm 9.3 \\
65.5 \pm 13.2\end{array}$ & $\begin{array}{l}81.5 \pm 15.3 \\
59.48 \pm 10.5\end{array}$ & 0.184 \\
ASA grades & & & 0.070 \\
$\quad$ Grade I & $16(53.3)$ & $18(60)$ & 0.479 \\
Grade II & $13(43.3)$ & $11(36.7)$ & \\
Grade III & $1(3.3)$ & $1(3.3)$ & \\
No. of patients $(\%)$ & & & 0.234 \\
Mean Age \pm SD $($ years $)$ & $55.8 \pm 16.5$ & $53.4 \pm 17.4$ & 0.64 \\
Gender & $28 \mathrm{M}(93.3)$ & $29 \mathrm{M}(96.7)$ & \\
Number $(\%)$ & $02 \mathrm{~F}(6.7)$ & $01 \mathrm{~F}(3.3)$ & 0.807 \\
Mean BMI \pm SD $\left(\mathrm{Kg} / \mathrm{m}^{2}\right)$ & $25.18 \pm 3.8$ & $25.42 \pm 3.4$ & 0.824 \\
Mean height $\pm \mathrm{SD}(\mathrm{cm})$ & $178.29 \pm 5.9$ & $177.85 \pm 8.1$ & \\
\hline
\end{tabular}

$S D$ standard deviation

\begin{tabular}{lllll}
\hline $\begin{array}{l}\text { Pain at different } \\
\text { time intervals }\end{array}$ & Pain at rest and coughing & $\begin{array}{l}\text { Control group } \\
\text { Mean } \pm \text { SD }\end{array}$ & $\begin{array}{l}\text { Intervention group } \\
\text { Mean } \pm \text { SD }\end{array}$ & $p$ value \\
\hline Pain at $3 \mathrm{~h}$ & Pain at rest & $3.1 \pm 1.1$ & $1.1 \pm 1.0$ & $<0.001^{*}$ \\
& Pain on coughing & $4.8 \pm 1.1$ & $2.1 \pm 1.5$ & $<0.001^{*}$ \\
Pain at $6 \mathrm{~h}$ & Pain at rest & $4.1 \pm 1.2$ & $1.7 \pm 1.1$ & $<0.001^{*}$ \\
& Pain on coughing & $5.4 \pm 1.4$ & $3.0 \pm 1.5$ & $<0.001^{*}$ \\
Pain at $24 \mathrm{~h}$ & Pain at rest & $3.6 \pm 1.0$ & $2.9 \pm 1.2$ & $0.035^{*}$ \\
& Pain on coughing & $5.3 \pm 1.0$ & $4.6 \pm 1.3$ & 0.09 \\
\hline
\end{tabular}

Pain assessed by VAS (0-10)

$S D$ standard deviation

*Statistically significant 
Table 3 Secondary outcomes: peri-operative analgesic consumption and patient satisfaction levels

\begin{tabular}{lccc}
\hline Secondary outcomes & $\begin{array}{c}\text { Control group } \\
\text { Mean } \pm \text { SD }\end{array}$ & $\begin{array}{l}\text { Intervention group } \\
\text { Mean } \pm \text { SD }\end{array}$ & $p$ value \\
\hline Intra-operative fentanyl (mcg) & $177.7 \pm 40$ & $148.1 \pm 44.8$ & $0.004^{*}$ \\
Peri-operative morphine (mg) & $8.3 \pm 1.8$ & $7.22 \pm 2.6$ & 0.12 \\
Tapentadol as rescue analgesia (mg) & $169.4 \pm 49.1$ & $71.3 \pm 48.8$ & $<0.001^{*}$ \\
Patient satisfaction score (0-10) & $6.8 \pm 0.9$ & $8.0 \pm 1.5$ & $<0.001^{*}$ \\
\hline
\end{tabular}

$S D$ standard deviation

*Statistically significant

\section{Discussion}

This double-blind randomized controlled trial has demonstrated the beneficial therapeutic effect of laparoscopicassisted TAP block in post-operative pain management for patients undergoing laparoscopic TEP inguinal hernia repair. The superiority of laparoscopic-assisted TAP block over conventional periportal block in terms of post-operative pain management has already been established by our group in laparoscopic cholecystectomy [10]. Over the last decade, multiple studies have been performed to evaluate the efficacy of both ultrasound-guided TAP and laparoscopic-assisted TAP block in various surgical procedures [7-11].

Laparoscopic inguinal hernia repair is now widely utilized as a day case procedure. Post-operative pain management has an important role in the ambulatory setting. Our study has demonstrated that post-operative pain scores were reduced at 3 and $6 \mathrm{~h}$, both at rest and on coughing, with statistically significant $p$ values recorded. The beneficial effect of the laparoscopic-assisted TAP block approach was also evident at $24 \mathrm{~h}$ at rest although mean pain scores were higher compared with the first 6-h period after surgery consistent with the physiological mechanism of action of Bupivacaine. Although the focus of the current study was not to quantify the actual length of hospital stay in hours, we believe that the laparoscopic-assisted TAP block technique has the potential to facilitate hospital discharge within $3 \mathrm{~h}$ post-surgery. This in turn may increase operating room productivity. Similar therapeutic effects to those observed in the current study have been reported in post-operative pain management for laparoscopic inguinal hernia repair utilizing ultrasoundguided rectus sheath and transversus abdominis plane blocks [12]. Another recent study has reported reduced post-operative pain scores up to $24 \mathrm{~h}$ after laparoscopic inguinal hernia repair comparing ultrasound-guided TAP block with periportal block [13].

Other studies have used various local anaesthetic agents, with different strengths, half-lives and mode of delivery [8-13]. In our study, total dosage administered for lapa-

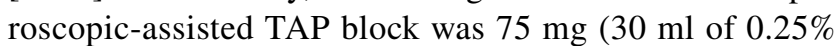
Bupivacaine). The periportal area was infiltrated with $15 \mathrm{ml}$ of $0.5 \%$ Bupivacaine that also constitutes a total dosage of
$75 \mathrm{mg}$. The volume and dosage of Bupivacaine selected for patients undergoing periportal infiltration with local anaesthetic ( $15 \mathrm{ml} \mathrm{0.5 \%} \mathrm{Bupivacaine} \mathrm{solution)} \mathrm{were} \mathrm{specifically}$ chosen to replicate established clinical practice.

Complications of TAP block are rare. There were no complications associated with laparoscopic-assisted TAP block in our study. In the literature, very few but significant complications have been reported with ultrasound-guided TAP block including liver injury [16, 17]. Because laparoscopicassisted TAP block is performed under vision, the risk of visceral injury is minimal. To date, there have been no complications reported with the use of the laparoscopic-assisted TAP block technique [9-11]. There was no significant difference between control and intervention groups with respect to operating and anaesthetic times confirming that the laparoscopic-assisted TAP block technique can be administered with minimal impact on the duration of surgery. However, studies have shown an increase in total anaesthetic time in patients undergoing ultrasound-guided TAP block [13, 14].

The current study demonstrated a significant reduction in rescue analgesic requirements in the intervention group as compared with the control group. There was also a significant decrease in intra-operative fentanyl requirements in the intervention group. Similar findings have been reported by Arora et al. utilizing the ultrasound-guided TAP block technique [13]. We also observed that patient satisfaction levels were higher in the intervention group as compared to the control group. A previous trial showing the effect of laparoscopic-assisted TAP block in patients undergoing colonic resection demonstrated reduction in morphine consumption and higher patient satisfaction levels [14]. In our study, there was no significant difference in peri-operative morphine requirements.

Various studies have shown the beneficial effects of TAP block as a component of multi-modal analgesia [9-11, 18]. The current study replicates the findings of our previous trial confirming the therapeutic effects of TAP block in post-operative pain management [10]. Our experience shows that laparoscopic-assisted TAP block is an efficient and easily transferable technique with high levels of patient safety. However, there is no randomized controlled trial reported to date to compare the efficacy and accuracy of 
ultrasound-guided and laparoscopic-assisted TAP block in laparoscopic inguinal hernia repair. There is now sufficient published evidence to routinely recommend laparoscopicassisted TAP blocks in elective inguinal hernia repairs, cholecystectomies, and laparoscopic colon resections [9-11, 18]. We are currently conducting further studies to evaluate the suitability of this technique in other laparoscopic elective and emergency procedures.

\section{Conclusion}

Laparoscopic-assisted TAP block is effective in post-operative pain management as a component of multi-modal analgesia in patients undergoing total extraperitoneal (TEP) repair of inguinal hernia. It not only significantly reduces pain scores but also decreases rescue analgesic requirements, thereby improving patient outcomes. We, therefore, recommend this technique to be used routinely in total extraperitoneal (TEP) repair of inguinal hernias.

Acknowledgements The authors would like to thank the nursing and theatre staff at MUH.

Author contributions Study conception and design: AM, AK, WK, and IZK; acquisition of data: JR, HN, MR, and AK; analysis and interpretation of data: $\mathrm{AM}, \mathrm{KB}$, and $\mathrm{MD}$; drafting of manuscript: $\mathrm{AM}, \mathrm{RW}, \mathrm{KB}$, and IZK; critical revision: RW, MD, WK, KB, and IZK

\section{Compliance with ethical standards}

Conflict of interest Dr. AM declares no conflict of interest related to the submitted work. Dr. AK declares no conflict of interest related to the submitted work. Dr. JR declares no conflict of interest related to the submitted work. Dr. MR declares no conflict of interest related to the submitted work. Dr. HN declares no conflict of interest related to the submitted work. Dr. RW declares no conflict of interest related to the submitted work. Dr. MD declares no conflict of interest related to the submitted work. Dr. WK declares no conflict of interest related to the submitted work. Dr. KB declares no conflict of interest related to the submitted work. Dr. IZK declares no conflict of interest related to the submitted work

Ethical approval Ethical approval was agreed by the ethical committee of our institution, Mayo University Hospital (MUH) Castlebar, Ireland.

Human and animal rights Study including human participants has been performed in accordance with ethical standards of Declaration of Helsinki and its later amendments.

Informed consent Informed consent was obtained from all patients prior to all surgical procedures.

Open Access This article is distributed under the terms of the Creative Commons Attribution-NonCommercial 4.0 International License (http://creativecommons.org/licenses/by-nc/4.0/), which permits any noncommercial use, distribution, and reproduction in any medium, provided you give appropriate credit to the original author(s) and the source, provide a link to the Creative Commons license, and indicate if changes were made.

\section{References}

1. Jenkins JT, O Dwyer PJ (2008) Inguinal hernias. BMJ 336:269272. https://doi.org/10.1136/bmj.39450.428275.AD

2. Benjamin Woods BS, Leigh Neumayer MD (2008) MS Open repair of inguinal hernia: An evidence-based review. Surg Clin North Am 88:139-155

3. Carter J, Duh Q-Y (2011) Laparoscopic repair of inguinal hernias. World J Surg 35:1519-1525. https://doi.org/10.1007/s0026 8-011-1030-x

4. Pawanindra Lal RK, Kajla J et al (2003) Randomized controlled study of laparoscopic total extraperitoneal versus open Lichtenstein inguinal hernia repair. Surg Endoscopy Other Intervent Tech 17:850-856. https://doi.org/10.1007/s00464-002-8575-6

5. Nicholson T, Tiruchelvam V (1999) Comparison of laparoscopic vs open modified shouldice technique in inguinal hernia repair. JSLS 3:39-43

6. Rafi AN (2001) Abdominal field block: a new approach via the lumbar triangle. Anaesthesia 56:1024-1026

7. Hebbard P, Fujiwara Y, Shibata Y, Royse C (2007) Ultrasound guided transversus abdominis plane block. Anaesth Intensive Care 35:616-617

8. O'Donnell BD, McDonnell JG, McShane AJ (2006) The transversus abdominis plane (TAP) block in open retropubic prostatectomy. Reg Anesth Pain Med 31:91

9. Chetwood A, Agrawal S, Hrouda D et al (2011) Laparoscopicassisted transversus abdominis plane block: a novel insertion technique during laparoscopic nephrectomy. Anaesthesia 66:317-318

10. Elamin G, Waters PS, Hamid $\mathrm{H}^{1}$ et al. Efficacy of a laparoscopically delivered transversus abdominis plane block technique during elective laparoscopic cholecystectomy: a prospective, doubleblind randomized trial. J Am Coll Surg. 2015; 221:335-344

11. Keller DS, Ermlich BO, Schiltz N (2014) The effect of transversus abdominis plane blocks on postoperative pain in laparoscopic colorectal surgery: a prospective, randomised, double-blind trial. Dis Colon Rectum 57:1290-1297

12. Takebayashi K, Matsumura M, Kawai Y (2015) Efficacy of transversus abdominis plane block and rectus sheath block in laparoscopic inguinal hernia surgery. Int Surg 100:666-671

13. Arora S, Subramaniam R, Arora MK (2016) Transversus abdominis plane block for laparoscopic inguinal hernia repair: a randomised trial. J Clin Anesth 33:357-364

14. Kim MG, Kim SI, Ok SY et al (2012) The analgesic effect of ultrasound-guided transverse abdominis plane block after laparoscopic totally extraperitoneal hernia repair. Korean J Anesthesiol 63:227-232. https://doi.org/10.4097/kjae.2012.63.3.227

15. Yang X-F, Liu J-L (2016) Anatomy essentials for laparoscopic inguinal hernia repair. Ann Trans Med 4:372. https://doi. org/10.21037/atm.2016.09.32

16. Farooq M, Carey M (2008) A case of liver trauma with a blunt regional anaesthesia needle while performing the transversus abdominis plane block. Reg Anesth Pain Med 33:274-275

17. Lancaster P, Chadwick M (2010) Liver trauma secondary ultrasound-guided transversus abdominis plane block. Br J Anaesth 104:509-510

18. Favuzza J, Delaney CP (2013) Outcomes of discharge after elective laparoscopic colorectal surgery with transversus abdominis plane blocks and enhanced recovery pathway. J Am Coll Surg 217:3503-3506 